\title{
Evidence-Based Medicine: An Overview of Available Evaluation Instruments
}

\author{
Romulo N. Aguilar \\ College of Medicine, University of the Philippines, Manila, Philippines
}

\section{How to cite}

Aguilar, R. N. (2019). Evidence-Based Medicine: An Overview of Available Evaluation Instruments. Asia Pacific Journal on Curriculum Studies, 2(1), 28-32. https://doi.org/10.53420/apjcs.2019.4

\begin{abstract}
The paradigm shift to evidence-based medical education was introduced many years back, driven mainly by the voluminous amount of medical literature available to both the medical student and practitioner as well. In essence, it provided a process for critically appraising available information for the purpose of obtaining the "best available evidence." Presently, as we continue to teach evidence-based medicine (EBM), we find it most useful to evaluate its effectiveness by devising ways to evaluate the performance not only of the students but, of medical practitioners and teachers of EBM as well. Performance evaluation of students involve evaluating the ability to ask answerable questions, perform a systematic search of literature, critically appraise the evidence and, integrate evidence and patient's values. A step further is to ask whether what we have learned has been translated into better clinical outcomes. Finally, we evaluate the teaching of EBM. This would necessitate much introspection as teachers ask themselves whether they have taught EBM effectively. Several evaluation instruments have already been developed over the years, but studies have shown that better tools still need to be developed.
\end{abstract}

Keywords: evidence-based medicine, evidence-based practice, evidence-based health care, evaluation, evaluation instruments, evaluation tools

\section{Introduction}

Medical literature has been expanding exponentially. Between 1978 and 2001, there were about 8.1 million journal articles published in MEDLINE. On average, over 450,000 articles are added every year (Druss \& Marcus, 2005). Densen (2011) estimated that the doubling time of medical knowledge will only be 73 days by the year 2020 . The expansion of medical knowledge obviously outpaces the ability of the individual to assimilate these information. For a health care professional to keep abreast, it was estimated way back in 1995 that he or she must read 19 articles every single day of the year (Davidoff, Haynes, Sackett \& Smith, 1995).

Evidence-based medicine (EBM) was developed in order to address this dilemma. EBM is the integration of best research evidence into one's clinical expertise and the patient's unique values and circumstances. The birth of EBM is largely attributed to David Sackett (1981), the acknowledged "Father of EBM," who published a series of articles that dealt with how to appraise medical literature. But, prior to this, the concept of "levels of evidence" has already been introduced by the Canadian Task Force on Periodic Health Examination (Djulbegovic \& Guyatt, 2017). Sackett revised this rating system in 1989. It was Gordon Guyatt (1991), a student of Sackett, who introduced the term "Evidence based medicine" in 1991. This was followed by the formation of the Cochrane Collaboration and the Library in 1993.

Since its introduction, EBM has slowly been integrated into the medical curriculum, as well as in the training programs of various medical institutions. So much so, an evidence-based approach to health care delivery is now recognized as a key competency for health care practitioners (Young, Rohwer, Volmink \& Clarke, 2014).

But, as in most educational processes, evaluation and feedback becomes necessary after a time. Shaneyfelt, et al. (2006), who published a systematic review of available tools for the evaluation of EBM stated that, "Teaching of EBP should be evaluated and guided by evidence of its own effectiveness." 


\section{Challenges to the Evaluation of EBM}

Evaluating the effectiveness of EBM is quite daunting because of the multifaceted nature of the discipline.

Firstly, EBM is both taught and practiced. Therein lies the primary dichotomy within which EBM should be evaluated. EBM, whether taught or practiced, consist of multiple steps namely, (1) "Asking” or formulating an answerable clinical question, (2) "Accessing" or searching for the best evidence, (3) "Appraising" the evidence for validity and usefulness, (4) "Applying" the results on a specific clinical scenario, and (5) "Assessing" or evaluating the effectiveness of the process. Within the context of either teaching EBM or practicing EBM, the challenge is evaluating all of these steps with a single tool versus evaluating each step independently of each other.

Second, in the application of the principles of EBM, there emerges three (3) subsets of practitioners: (1) the so-called "Doers" who apply all five steps, (2) the "Users" who search for and apply pre-appraised evidence, and (3) the "Replicators" who seek advice from the doers (Young, Rohwer, Volmink \& Clarke, 2014). Herein arise the question of whether evaluation tools should be designed to cater to each of the three subsets.

Third, several domains need to be evaluated, namely: (1) knowledge, (2) skills, (3) behavior, (4) attitude, and (5) patient outcomes.

Finally, within the context of teaching EBM, all of the above mentioned aspects might need to be evaluated against the hierarchy of the medical education infrastructure: the teacher, the medical student (of which there are various year levels), and the medical intern. Likewise, in the realm of practice of EBM, there exist multiple tiers: the postgraduate trainee or resident, the fellow, the young consultant, and the experienced practitioner. What complicates matters is that, in the latter, the teaching and application of the principles of EBM follows a relatively less structured approach compared to the well-structured medical curriculum of medical students. Evaluation methods might have to consider these differences.

\section{Evaluation tools}

Table 1.

EBM is taught by means of any of the interventions in the left column. Evaluation may be carried out using one or a combination of tools listed in the right column (Shaneyfelt, et al., 2006; Young, Rohwer, Volmink \& Clarke, 2014)

\begin{tabular}{ll}
\hline \multicolumn{1}{c}{ Interventions } & \multicolumn{1}{c}{ Known Evaluation Tools } \\
\hline EBM lectures & Multiple choice questions \\
EBM workshops & Open-ended free-text questions \\
Integrated teaching of EBM & Fill-in-the-blank questions \\
Online teaching of EBM & Case-based problems \\
Journal clubs & Analysis of audio tapes \\
Practical sessions & Library system electronically capturing search strategy \\
& Record audit for physician performance \\
& Internet based portfolio \\
\hline
\end{tabular}

Table 1 shows the diverse approach to teaching EBM and the equally diverse set of tools used to evaluate EBM (Shaneyfelt, et al., 2006; Young, Rohwer, Volmink \& Clarke, 2014). To date, there is no one tool to evaluate EBM.

The most rudimentary evaluation form was introduced by the Evidence Based Working Group (1992). It consisted of evaluating only two domains: (1) whether one is a role model of the practice of EBM, or (2) whether one leads the practice of EBM. A descriptive rating scale ranging from unsatisfactory to excellent was used (Table 2).

Table 2 .

Evaluation Form for Clinical Teaching Unit Attending Physicians (Evidence-Based Medicine Working Group, 1992)

\begin{tabular}{|c|c|c|c|c|c|}
\hline \multirow[b]{2}{*}{ Domain } & \multicolumn{5}{|c|}{ Rating } \\
\hline & Unsatisfactory & $\begin{array}{c}\text { Needs } \\
\text { Improvement }\end{array}$ & Satisfactory & Good & Excellent \\
\hline $\begin{array}{l}\text { Role model } \\
\text { of practice } \\
\text { of evidence- }\end{array}$ & $\begin{array}{l}\text { Seldom cites } \\
\text { evidence to }\end{array}$ & $\begin{array}{l}\text { Often fails to } \\
\text { substantiate }\end{array}$ & $\begin{array}{l}\text { Usually } \\
\text { substantiates }\end{array}$ & $\begin{array}{l}\text { Substantiates } \\
\text { decisions; is } \\
\text { aware of }\end{array}$ & $\begin{array}{l}\text { Always } \\
\text { substantiates } \\
\text { decisions or }\end{array}$ \\
\hline
\end{tabular}




\begin{tabular}{|c|c|c|c|c|c|}
\hline $\begin{array}{l}\text { based } \\
\text { medicine }\end{array}$ & $\begin{array}{l}\text { support clinical } \\
\text { decisions }\end{array}$ & $\begin{array}{l}\text { decisions with } \\
\text { evidence }\end{array}$ & $\begin{array}{l}\text { decisions with } \\
\text { evidence }\end{array}$ & $\begin{array}{l}\text { methodological } \\
\text { issues }\end{array}$ & $\begin{array}{l}\text { acknowledges } \\
\text { limitations of } \\
\text { evidence }\end{array}$ \\
\hline $\begin{array}{l}\text { Leads } \\
\text { practice of } \\
\text { evidence- } \\
\text { based } \\
\text { medicine }\end{array}$ & $\begin{array}{l}\text { Never assigns } \\
\text { problems to be } \\
\text { resolved through } \\
\text { literature }\end{array}$ & $\begin{array}{l}\text { Produces } \\
\text { suboptimal } \\
\text { volume or } \\
\text { follow-through } \\
\text { of problem } \\
\text { resolution } \\
\text { through literature }\end{array}$ & $\begin{array}{l}\text { Assigns problems } \\
\text { and follows } \\
\text { through with } \\
\text { discussion, } \\
\text { including } \\
\text { methodology }\end{array}$ & $\begin{array}{l}\text { Discusses } \\
\text { literature retrieval, } \\
\text { methodology of } \\
\text { papers, } \\
\text { application to } \\
\text { individual patient }\end{array}$ & $\begin{array}{l}\text { Same as "Good" } \\
\text { rating, and makes } \\
\text { it exciting and fun }\end{array}$ \\
\hline
\end{tabular}

Over the years, many more much sophisticated instruments were developed. Because there existed numerous tools for the evaluation of EBM, Shaneyfelt, et al. (2006) undertook a systematic review to appraise, summarize, and describe available EBP teaching evaluation instruments.

From a review of 115 articles, 104 unique instruments were identified. Of these, majority were commonly administered to medical students (43/104 or $41.3 \%$ ) and postgraduate trainees (35/104 or 33.7\%). Only 30 of the $104(28.8 \%)$ were designed for practicing physicians. Among the EBM domains, skills were the most evaluated, which was detected in 59 instruments. This was followed by knowledge and behaviors (39 instruments each), and attitudes (27 instruments). Patient outcomes was the least evaluated with only 2 instruments focusing on the said domain.

The review categorized the evaluation instruments into three (3) levels. Level 1 instruments were those that could discriminate between different levels of expertise or performance. They had robust psychometric properties and multiple validities. Level 1 instruments are best used for documenting competence of individual trainees and for formative and summative evaluations. Examples of these instruments are the Fresno test and Berlin questionnaire.

Level 2 instruments exhibited strong evidence of responsive validity. These are best used for programmatic, rather than individual, evaluation of the impact of EBP interventions.

Level 3 instruments were those that did not have strong evidence of responsive validity. These instruments are recommended for the evaluation of EBP behavior.

The review further observed that evidence-based practice learning portfolios represent the most promising approach to document the performance of EBP steps. It also noted that there are less tools for evaluating attitudes and behaviors compared to instruments used to evaluate knowledge and skills.

Rengerink, et al. (2013) carried out a systematic review aimed at identifying and comparing tools used to evaluate EBP behavior among healthcare professionals. The review included 160 different evaluation tools used in 172 studies. The review found that most tools were valid and reliable but assessed only single steps in the EBP process. Only one (1) evaluation tool measured all 5 steps of the EBP process. While this tool was considered valid, it was not tested for reliability.

Most tools included in the review were found to focus on the evaluation of the second step of the EBP process, which is accessing or searching for the best available evidence, and failed to show the integration of evidence with clinical expertise and patients' values. Thus, these tools provide only a very limited view of EBP behavior.

Alborquoni, Hoffman \& Glasziou (2018) published a systematic review which evaluated the properties of the instruments that are used to assess EBP educational interventions. In other words, they looked at what is taught and how these were measured. They evaluated six (6) so-called "high quality" instruments used in 85 included studies. Among these six instruments were the Fresno test and Berlin questionnaire, which were also included in the systematic review conducted by Shaneyfelt, et al. (2006). They concluded that, "Majority of evaluated EBP educational interventions remain focused on critically appraising evidence (EBP Step 3), often to the exclusion of other steps. There are few validated instruments that have been developed and utilized in EBP educational intervention studies; and these predominantly focus on certain domains (i.e. knowledge and skills) and EBP steps (i.e. appraise). This might limit the ability to evaluate the impact of EBP educational interventions."

Knowing what to evaluate would greatly aid in the development of appropriate evaluation tools or instruments. Thus, a consensus statement was published defining the core competencies that a healthcare professional must possess in an evidence-based practice (Alborquoni, et al., 2018). From 83 EBP educational interventional studies, they were able to generate 86 unique EBP core 
competencies. The core competencies involved all five steps of the EBP process, namely, (1) Ask, (2) Acquire, (3) Appraise and Interpret, (4) Apply, and (5) Evaluate. Table 3 shows a list of the primary core competencies.

Table 3

There are 27 primary core competencies under each of which are subsets of competencies to be evaluated. The full list may be obtained from the paper of Alborquoni, et al. (2018)

\begin{tabular}{|c|c|}
\hline \multicolumn{2}{|l|}{ EBP Core Competencies } \\
\hline \multicolumn{2}{|l|}{ 0. Introductory } \\
\hline \multicolumn{2}{|l|}{$\begin{array}{l}0.1 \text { Understand EBP defined as the integration of the best research evidence with clinical expertise and patient's unique } \\
\text { values and circumstances }\end{array}$} \\
\hline \multicolumn{2}{|l|}{0.2 Recognize the rationale for EBP } \\
\hline \multicolumn{2}{|l|}{$\begin{array}{l}0.3 \text { For each type of clinical question, identify the preferred order of study designs, including the pros and cons of the } \\
\text { major study designs }\end{array}$} \\
\hline \multirow{2}{*}{\multicolumn{2}{|c|}{$\begin{array}{l}\text { 0.4 Practice the } 5 \text { steps of EBP: ask, acquire, appraise and interpret, apply, and evaluate } \\
0.5 \text { Understand the distinction between using research to inform clinical decision making vs conducting research }\end{array}$}} \\
\hline & \\
\hline \multicolumn{2}{|l|}{ 1. Ask } \\
\hline \multirow{2}{*}{\multicolumn{2}{|c|}{$\begin{array}{l}\text { 1.1 Explain the difference between the types of questions that cannot typically be answer } \\
\text { questions) and those that can (foreground E questions) } \\
\text { 1.2 Identify different types of clinical questions, such as questions about treatment, diagn } \\
\text { 1.3 Convert clinical questions into structured, answerable clinical questions using PICO }\end{array}$}} \\
\hline & \\
\hline \multicolumn{2}{|l|}{ 2. Acquire } \\
\hline \multicolumn{2}{|l|}{$\begin{array}{l}\text { 2.1 Outline the different major categories of sources of research information, includ } \\
\text { databases of filtered or preappraised E evidence or resources } \\
\text { 2.2 Construct and carry out an appropriate search strategy for clinical questions } \\
\text { 2.3 State the differences in broad topics covered by the major research databases } \\
\text { 2.4 Outline strategies to obtain the full text of articles and other evidence resources }\end{array}$} \\
\hline \multicolumn{2}{|l|}{ 3. Appraise and Interpret } \\
\hline \multicolumn{2}{|l|}{$\begin{array}{l}\text { 3.1 Identify key competencies relevant to the critical evaluation of the integrity, reliability, and applicability of health- } \\
\text { related research }\end{array}$} \\
\hline \multicolumn{2}{|l|}{ 3.2 Interpret different types of measures of association and effect, including key graphical presentations } \\
\hline \multicolumn{2}{|l|}{ 3.3 Critically appraise and interpret a systematic review } \\
\hline \multicolumn{2}{|l|}{ 3.4 Critically appraise and interpret a treatment study } \\
\hline \multicolumn{2}{|l|}{ 3.5 Critically appraise and interpret a diagnostic accuracy study } \\
\hline \multicolumn{2}{|l|}{ 3.6 Distinguish evidence-based from opinion-based clinical practice guidelines } \\
\hline \multicolumn{2}{|l|}{ 3.7 Identify the key features of, and be able to interpret, a prognostic study } \\
\hline \multicolumn{2}{|l|}{ 3.8 Explain the use of harm and etiologies study for (rare) adverse effects of interventions } \\
\hline \multicolumn{2}{|l|}{ 3.9 Explain the purpose and processes of a qualitative study } \\
\hline \multicolumn{2}{|l|}{ 4. Apply } \\
\hline \multirow{4}{*}{\multicolumn{2}{|c|}{$\begin{array}{l}\text { 4.1 Engage patients in the decision making process, using shared decision making, including explaining the evidence } \\
\text { and integrating their preferences } \\
\text { 4.2 Outline different strategies to manage uncertainty in clinical decision making in practice } \\
\text { 4.3 Explain the importance of baseline risk of individual patients when estimating individual expected benefit } \\
\text { 4.4 Interpret the grading of the certainty in evidence and the strength of recommendations in health care }\end{array}$}} \\
\hline & \\
\hline & \\
\hline & \\
\hline \multicolumn{2}{|l|}{ 5. Evaluate } \\
\hline $\begin{array}{l}\text { 5.1 Recognize potential individual-level barriers to knowledge translation and strategies to overcome th } \\
\text { 5.2 Recognize the role of personal clinical audit in facilitating EBP }\end{array}$ & \\
\hline
\end{tabular}

\section{Summary}

The multi-faceted nature of EBM/EBP leads to a complex process of evaluation. Presently available evaluation tools or instruments are inadequate to assess the totality of the EBM/EBP process. Most tools focus on searching (step 2) and critical appraisal of evidence (step 3). Only a few have been found to assess all 5 steps of the EBM process.

Majority of the instruments have been found to assess only the domain of skills, more than knowledge, attitude, behavior and patient outcomes. Hence, there is a need to develop more tools that would focus on attitude and behavior, and more importantly, that would evaluate the effect of EBM/EBP on patient outcomes. 
Of the instruments evaluated so far, only a limited number pass the tests for validity and reliability. A single or universal evaluation tool that is both valid and reliable is desirable, but difficult to develop.

\section{References}

Albarqouni, L., Hoffmann, T., \& Glasziou, P. (2018). Evidence-based practice educational intervention studies: A systematic review of what is taught and how it is measured. BMC Medical Education,18(1). doi:10.1186/s12909018-1284-1

Albarqouni, L., Hoffmann, T., Straus, S., Olsen, N. R., Young, T., Ilic, D., . . Glasziou, P. (2018). Core Competencies in Evidence-Based Practice for Health Professionals. JAMA Network Open, 1(2). https://doi.org/10.1001/jamanetworkopen.2018.0281

Davidoff, F., Haynes, B., Sackett, D., \& Smith, R. (1995). Evidence based medicine. BMJ, 310(6987), $1085-1086$. https://doi.org/10.1136/bmj.310.6987.1085

Densen, P. (2011). Challenges and Opportunities Facing Medical Education. Transactions of the American Clinical and Climatological Association, 122, 48-58.

Druss, B. G., \& Marcus, S. C. (2005). Growth and decentralization of the medical literature: implications for evidencebased medicine. Journal of the Medical Library Association: JMLA, 93(4), 499-501.

Djulbegovic, B., \& Guyatt, G. H. (2017). Progress in evidence-based medicine: a quarter century on. The Lancet, 390(10092), 415-423. https://doi.org/10.1016/s0140-6736(16)31592-6

Evidence-based medicine. A new approach to teaching the practice of medicine. Evidence-Based Medicine Working Group. (1992). JAMA: The Journal of the American Medical Association,268(17), 2420-2425.

https://doi.org/10.1001/jama.268.17.2420

Guyatt G. (1991). Evidence-based medicine. Annals of Internal Medicine,14(Supp 2): A-16.

Rengerink, K. O., Zwolsman, S. E., Ubbink, D. T., Mol, B. W., Dijk, N. V., \& Vermeulen, H. (2013). Tools to assess Evidence-Based Practice behaviour among healthcare professionals. Evidence Based Medicine,18(4), $129-138$. https://doi.org/10.1136/eb-2012-100969

Sackett, D. (1981). How to read clinical journals: I. why to read them and how to start reading them critically. 1981, 1245:555-558. Canadian Medical Association Journal, 1245, 555-558.

Shaneyfelt, T., Baum, K. D., Bell, D., Feldstein, D., Houston, T. K., Kaatz, S., .. Green, M. (2006). Instruments for Evaluating Education in Evidence-Based Practice. Jama, 296(9), 1116. https://doi.org/10.1001/jama.296.9.1116

Young, T., Rohwer, A., Volmink, J., \& Clarke, M. (2014). What Are the Effects of Teaching Evidence-Based Health Care (EBHC)? Overview of Systematic Reviews. PLoS ONE,9(1). https://doi.org/10.1371/journal.pone.0086706 